\title{
Identificando a Biodiversidade Local: \\ Uma Proposta de Ensino Interligando Estudantes, Tecnologia e Meio Ambiente
}

Márcia Ferreira de Souza ${ }^{1}$

Maria Dias de Brito $^{2}$

\begin{abstract}
RESUMO: Em 2010, ano Internacional da Biodiversidade, é de extrema importância conhecer o que temos em termos de diversidade biológica e o que podemos fazer para conservá-la, pois a exploração humana sobre os recursos naturais tem aumentado incontrolavelmente, assim, colocando em risco a biodiversidade que fornece o equilíbrio do planeta Terra, principalmente no Brasil, país megadiverso, mas que a população, em especial estudantes, "desconhecem". O objetivo do estudo é instigar os discentes do Ensino Fundamental Maior e Ensino Médio a identificarem a Biodiversidade de diferentes locais do município no qual residem e produzir uma vídeo-aula. Os discentes assistiram aulas discursivas, uma coletânea de vídeos-aulas sobre o tema e foram "a campo" para produzir a vídeo-aula. Foram produzidas cerca de 40 vídeo aulas dos locais visitados. Os principais fatores que ameaçam a biodiversidade, apontados pelos estudantes, foram à fragmentação de hábitat, a degradação do solo e o desmatamento.
\end{abstract}

Palavras-chave: biodiversidade; educação; vídeo aulas.

\section{INTRODUÇÃO}

O Brasil é o país mais megadiverso do planeta com cerca de duzentas mil espécies (LEWINSOHN e PRADO, 2002) e uma diversidade de biomas, dentre os quais os biomas da Mata Atlântica e Cerrado considerados hotspots da biodiversidade, ou seja, são áreas que possuem alta diversidade biológica, principalmente endêmica, e com alto índice de degradação ambiental (MYERS, 2000).

Em todos os biomas brasileiros ocorrem uma acelerada degradação ambiental com impactos de diferentes escalas espaciais, podendo ser constatados visualmente, em virtude da perda e fragmentação de hábitat, da poluição de nascentes e da descaracterização da natureza para construções, rodovias, etc. Apesar disso, a maioria da população, sente-se à parte das responsabilidades da conservação da diversidade bem como das questões ambientais.

Em meio a este "desconhecimento", encontram-se os muitos alunos do ensino fundamental e médio e até muitos de nível superior que desconhecem a importância da manutenção desta diversidade e da busca de alternativas sustentáveis às atividades

\footnotetext{
1 Graduada em Biologia Licenciatura pela Universidade Federal de Alagoas (UFAL, Campus Arapiraca). Mestranda em Diversidade Biológica e Conservação nos Trópicos (UFAL, Campus Maceió)

$2 \quad$ Graduada em biologia licenciatura pela Universidade Estadual de Alagoas (UNeal). Especialista em Educação

Ambiental. Atua no ensino Fundamental menor, maior e no Ensino Médio
} 
consumistas e destruidoras da atualidade que tanto ameaçam a manutenção da vida na Terra.

O âmbito escolar é considerado o lugar mais adequado para se trabalhar a relação homem-ambiente-sociedade, sendo um espaço propício para a formação de cidadãos críticos e criativos, com uma nova visão de mundo (BRONDANI e HENZEL, 2010).

Essa busca por um "mundo mais sustentável" tem sido abordada nas escolas, principalmente por conteúdos das disciplinas de "Ciências" no Ensino Fundamental e "Biologia" no Ensino Médio (ambas, muitas vezes em conjunto com a disciplina de "Geografia" ou por meio de projetos escolares). Estas associam aulas discursivas e muitos documentários sobre as questões ambientais como o aquecimento global, a degradação ambiental, doenças emergentes (resultado do desequilíbrio que está sendo criado a cada dia), destino do lixo, extinção de espécies, etc.

Dessa forma, o uso de tecnologias para a construção e disseminação do conhecimento está sendo implementada gradualmente nas escolas (visando também explorar a facilidade que os jovens atuais têm em manusear as mesmas).

Entretanto, mesmo possuindo um laboratório de informática, ou outras mídias disponíveis, às escolas atuais, principalmente as públicas, apresentam uma desconexão com conteúdos trabalhados com aqueles referentes à EA como oportunidade de transformar hábitos e atitudes que afetam o espaço e repensar o lugar em que o discente está inserido (GUEDES e VICTORINO, 2011).

O município de Arapiraca está localizado na região agreste do estado de Alagoas. É uma área de transição entre o bioma da Mata Atlântica e o bioma Caatinga. Por ser uma área de transição, possui espécies de animais e vegetais de ambos os biomas, é a segunda maior cidade do Estado e apresenta uma economia baseada na agricultura (principalmente no cultivo do fumo) e no comércio sendo considerada uma das futuras metrópoles do país (PERIARD, 2010). Apesar disso, têm se esquecido de reparar danos antrópicos ao ambiente. Dessa forma, o presente trabalho tem por objetivo principal instigar os discentes a conhecerem a diversidade biológica e os fatores responsáveis pela perda da diversidade em comunidades rurais, vilas e bairros do município.

\section{METODOLOGIA}

Os estudantes do Ensino Fundamental Maior e Ensino Médio (cerca de 1050) dos três turnos da Escola Estadual Senador Rui Palmeira - PREMEN, Arapiraca, Alagoas, Brasil, participaram do Projeto extracurricular intitulado de "I Amostra da BioVídeodiversidade de Arapiraca" para conhecer toda a diversidade biológica, bem como todos os fatores que a ameaçam em todas as áreas visitadas e a partir de então, produzir um vídeo aula expondo tudo o que foi observado em campo.

Para a execução desse projeto, os alunos tiveram orientações durante as aulas de Ciências/Biologia sobre o status da biodiversidade mundial, brasileira, de Alagoas e de Arapiraca com ênfase na importância da manutenção da mesma para o equilíbrio da cadeia alimentar de todo o planeta.

A segunda etapa do projeto foi desenvolvida quando os alunos assistiram a uma sessão de cinema com duas horas de duração de minivídeos sobre a biodiversidade, biomas, impactos provocados pelo destino incorreto do lixo, etc. disponíveis em sites da internet, como forma de nortear a execução de cada documentário produzido.

$\mathrm{Na}$ terceira etapa, os alunos retornaram à escola, sortearam uma localidade (do município) a ser estudada, sendo que foram selecionadas quarenta localidades entre urbanas e rurais que foram sorteadas entres todas as turmas participantes. 
$\mathrm{Na}$ quarta e última etapa, os alunos confeccionaram o vídeo-aula registrando a biodiversidade encontrada, o histórico de formação da localidade, bem como as alterações sofridas no hábitat descrito por moradores idosos na comunidade.

No quinto e último momento, em sessão especial, no cinema central da cidade, foram expostas à comunidade estudantil todas as produções confeccionadas. Ressalta-se que ambas as sessões de cinemas ocorreram nos dias de sábado, para não interferir no cronograma normal da escola.

\section{RESULTADOS E DISCUSSÃO}

Durante a realização das aulas foram discutidas questões tais como: a perda da biodiversidade e as suas consequências (extinção de espécies úteis ao homem). $E$ a importância do desenvolvimento de ações simples (p. ex.: colocar lixo no lixeiro) que contribuem expressivamente para a redução dos impactos humanos sobre outras espécies de animais, plantas etc.

Por meio das discussões em sala de aula buscou-se desenvolver um processo de conscientização ambiental tentando-se fazer com que os estudantes entendesse que o ambiente, no qual estamos inseridos, há inúmeras espécies de outros seres vivos que sofrem os impactos de nossas ações cotidianas que muitas vezes são esquecidas/ ignoradas tendo diversas consequências negativas para todos os indivíduos da área.

O uso de tecnologias para facilitar o processo de ensino - aprendizagem tem aumentado ultimamente. Os laboratórios de informática tem possibilitado a exploração de novas formas de ensinar, produzir e disseminar conhecimentos, principalmente relacionados à área da Educação ambiental que exigem ações formais (dentro das escolas = ensino e discussão) e ações não formais (fora delas para a conscientização e discussão da importância da conservação) e tendo como princípio norteador que essa educação deve ser entendida como algo dinâmico e que se adéqua a cada grupo e sua subjetividade (TELES, 2010) onde no ato de ensino não são expostas somente informações prontas e fechadas, os estudantes tiveram a oportunidade de serem os responsáveis pela elaboração dos documentários (vídeos-aulas), tiveram que pesquisar produzir e dar o melhor de si, ou seja, um projeto que parecia simples tornou-se em algo que movimentou os estudantes e certamente cada mente envolvida nesse processo aprendeu que é possível fazer algo para preservar a Biodiversidade local que refletirá na conservação da Biodiversidade global.

De acordo com Hernadez e Sancho (2007) os alunos adquirem uma formação a partir da experiência vivida, ou seja, a partir do que é vivenciado na prática, da experiência de ir a campo, produzir e expor suas experiências sobre determinado conteúdo, etc. As alternativas de ensino-aprendizagem tem ido além da sala de aula e tem oferecido aos discentes oportunidades de serem também disseminadores de conhecimento.

Nas aulas de campo, os alunos de cada turma entrevistaram os moradores mais antigos do local escolhido (por sorteio), para identificar e saber um pouco do histórico do local, especialmente o que existia de florestas, animais, recursos naturais (como água potável), etc.

As comunidades rurais apresentaram diversos cultivos e criação de animais em cativeiros, sendo os principais apresentados na Figura 1.

Muitas das ameaças registradas para às comunidades rurais também foram observadas nas áreas urbanas, como o exemplo de aves em cativeiro. Mas surgiram outros fatores como a elevada ocorrência de espécies exóticas, a poluição hídrica e a falta de consciência e conhecimento da população sobre as questões ambientais, ou seja, de conservação ambiental, o que exige futuras ações de educação ambiental. 


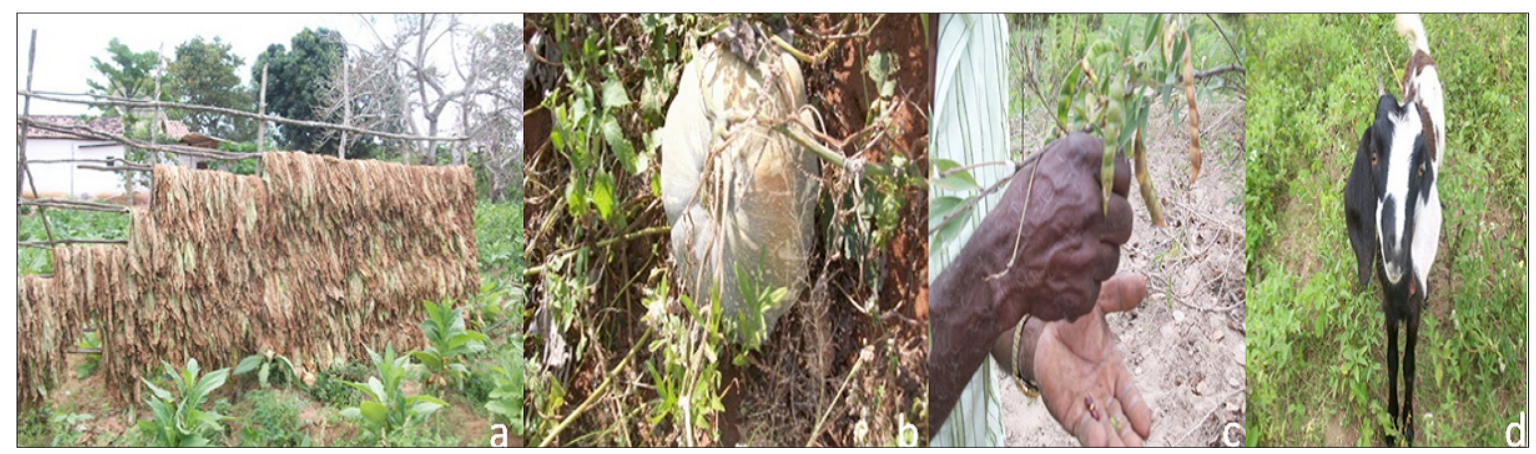

Figura 1: Cultivos desenvolvidos nas localidades rurais visitadas. Fumicultura (a), abóbora (b), feijão-andu (c) criação de caprinos (d).

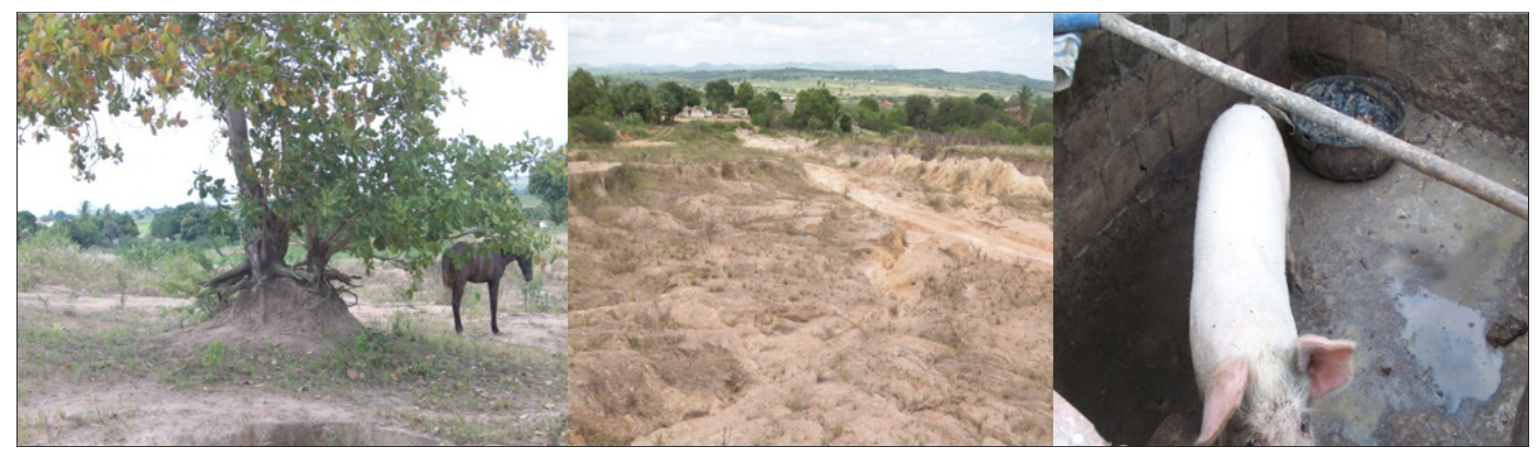

Figura 2: Principais impactos registrados pelos discentes. Desmatamento e extração de areia (a), erosão (b) e animais em cativeiro sem a devida higienização (c).

Em todas as comunidades, vilas e bairros visitados, foi perceptível a presença de pouquíssimas espécies nativas de plantas, exceto, nas comunidades rurais do Carrasco e da Massaranduba que possuem um relevo "montanhoso", ou seja, com serras/serrotes que ainda preserva uma mata que possui espécies de plantas nativas da região.

Como esperava, as comunidades rurais apresentaram maior abundância de espécies, que geralmente estão intimamente relacionadas com benefício ao homem, ou seja, são exploradas pelo homem de alguma forma (frutíferas, leguminosas, floríferas, etc.). Foi notável a presença de aves em cativeiros, principalmente Passeriformes, tanto espécies nativas quanto exóticas, mas a identificação ocorreu apenas pelo nome popular. A alta ocorrência de espécies exóticas poderá ocasionar a perda da biodiversidade, pois ocupa o habitat das espécies nativas e geralmente não possuem predadores específicos e aumenta exageradamente a população em curto período de tempo (MARTINS e SANO, 2009).

Os principais fatores apontados como responsáveis pela perda da biodiversidade na região foram o desmatamento e queimada da vegetação para a cultura do fumo - além de necessitar de áreas para plantio, necessita-se do emprego de muitos insumos químicos sintéticos e altamente tóxicos a seres vivos não-alvo do controle. Esses fatores não são diferentes dos observados em outros estudos como o de Garcia e Rovere (2008). Já as localidades urbanas apresentaram, em sua maioria, problemas relacionados ao lixo, esgoto etc.

Em relação aos recursos hídricos disponíveis, as comunidades rurais obtêm-nos de barragens ou açudes (escavações construídas para acumular água durante as estações chuvosas, geralmente é muito turva devido a sedimentação que é arrastada pela enxurrada e também não é tratada antes de ser consumida), cacimbas (poços escavados que obtêm água do subsolo) e a água canalizada do rio São Francisco que é utilizada tanto na área urbana e em muitas comunidades rurais, mas o abastecimento é insuficiente. Além da ausência de saneamento básico nos bairros periféricos, praticamente não há espécies nativas, exceto algumas plantas símbolos (como a planta de "Arapiraca" que deu nome ao município), sendo as demais exóticas em sua maioria exótica (ex. Ficus sp.). 
De forma geral, os discentes conheceram e caracterizaram os locais visitados. Além de realizarem a identificação da perda da biodiversidade, pois nas entrevistas com as pessoas mais idosas, pode-se perceber que as ações antrópicas são capazes de transformar um ambiente biodiverso e equilibrado naturalmente em solos expostos e pobres em nutrientes, esgotados pela ação humana.

As espécies de animais que há cerca de quatro décadas eram tão freqüentes, hoje se apresentam extremamente raros, consequência da fragmentação das matas, da caça excessiva, de queimadas, etc. As crianças de tais localidades as histórias do que existia em Arapiraca, mas dificilmente poderão contemplar toda a biodiversidade já existente em décadas passadas. Essa degradação é fruto de um desenvolvimento econômico desordenado e rápido, marcado pela descaracterização da área e pelo descaso com a natureza.

Conclui-se que essa metodologia de ensino-aprendizagem: de possibilitar o contato dos estudantes com o objeto estudado se faz necessário, pois os fomenta a repensarem seus atos e transforma-os em produtores e disseminadores do conhecimento em sua volta no que refere a identificação da biodiversidade local e as conseqüências da perda desta para a biodiversidade regional e global, uma vez que as espécies são extintas uma única vez, por isso é de extrema relevância realizar a conscientização na vivência prática com a natureza.

\section{REFERÊNCIAS}

BRONDANI, C. J.; HEZEL, M. E. Análise sobre a conscientização ambiental em escolas da rede municipal de ensino. Rev. Bras. de Educação Ambiental, Rio Grande, v. 5, n. 1, 2010 .

GARCIA, K. C., ROVERE, E. L. Riscos à biodiversidade no setor de petróleo e gás natural offshore do Brasil. Cadernos da Biodiversidade. v. 5, n. 2, jan. 2008 .

LEWINSOHN, T. M., PRADO, P. I. Biodiversidade brasileira: síntese do estado atual do conhecimento. São Paulo: Contexto, 2002.

MARTINS, M. R. C., SANO, P. T. Biodiversidade tropical. São Paulo: UNESP, 2009.

MYERS, N.; MITTERMEIER, R. A.; MITTERMEIER, C. G.; FONSECA, G. A. B.; KENT, J. Biodiversity hotspots for conservation priorities. Nature, v. 403, february, 2000.

PERIARD, G. As metrópoles do futuro. As $\mathbf{2 0}$ cidades brasileiras do futuro, São Paulo, 28 ago. 2010. Edição Especial.

TELES, A. M. O. A dimensão subjetiva na educação ambiental. Rev. Bras. de Educação Ambiental, Rio Grande, v. 5, n. 1, 2010. 